\title{
Inhaled prostacyclin analogues in COVID-19 associated acute respiratory distress syndrome: scientific rationale
}

\author{
Eka Prasetya Budi Mulia ${ }^{{ }^{*}}$ (D) and Kevin Luke ${ }^{2}$ (D)
}

\begin{abstract}
Background: COVID-19 associated acute respiratory distress syndrome (CARDS) is a severe form of SARS CoV-2 infection and affects about 15-30\% of hospitalized patients with a high mortality rate. Growing research and data suggest several available drugs with appropriate pharmacological effects to treat COVID-19.

Main body: Prostacyclin analogues are regiments for pulmonary artery hypertension. Prostacyclin analogues are expected to be beneficial in treating CARDS based on at least four rationales: (1) inhaled prostacyclin analogues improve oxygenation, V/Q mismatch, and act as an ARDS therapy alternative; (2) it alleviates direct SARS-CoV-2-related coagulopathy; (3) increases nitric oxide production; and (4) possible anti-inflammatory effect. Prostacyclin analogues are available in oral, intravenous, and inhaled forms. The inhaled form has the advantage over other forms, such as parenteral administration risks. Previously, a meta-analysis demonstrated the beneficial effects of inhaled prostaglandins for ARDS treatment, such as improved $\mathrm{PaO} 2 / \mathrm{FiO} 2$ and $\mathrm{PaO} 2$ along with reduced pulmonary artery pressure. Currently, two ongoing randomized controlled trials are evaluating inhaled epoprostenol (VPCOVID [NCT04452669]) and iloprost (ILOCOVID [NCT04445246]) for severe COVID-19 patients.
\end{abstract}

Conclusions: Inhaled prostacyclin could be considered in patients with refractory, life-threatening hypoxia despite standard management.

Keywords: ARDS, COVID-19, Epoprostenol, Prostacyclin

\section{Background}

COVID-19 caused by SARS-CoV-2 has posed enormous challenges to healthcare systems in the world. Currently, no therapeutic agent has been thoroughly proven against the disease. Growing research and clinical data regarding the virology and pathophysiology of SARS-CoV-2 suggest several reused drugs with appropriate pharmacological effects and therapeutic efficacy in treating patients with COVID-19 [1].

\footnotetext{
*Correspondence: eka.prasetya.budi-2017@fk.unair.ac.id

1 Department of Cardiology and Vascular Medicine, Faculty of Medicine, Universitas Airlangga - Dr. Soetomo General Hospital, Jl. Mayjen Prof. Dr. Moestopo No.6-8, Surabaya 60286, Indonesia

Full list of author information is available at the end of the article
}

Most patients hospitalized for COVID-19 develop complications of acute respiratory distress syndrome (ARDS) or respiratory failure. ARDS is an acute inflammatory lung injury associated with increased pulmonary vascular permeability and loss of aerated lung tissue, affecting $23 \%$ of mechanically ventilated critically ill patients. In-hospital ARDS mortality is estimated to be between 35 and $46 \%$, depending on the severity of ARDS [2]. However, the mortality rate in COVID-19 with ARDS seems to be higher, ranging from 13 to $73 \%$ [3].

Prostacyclin is a potent vasodilator of all vascular beds and an endogenous inhibitor of platelet aggregation. The antithrombotic effect results from the activation of intracellular adenylate cyclase and an increase in cyclic adenosine monophosphate (cAMP) in platelets. These agents include epoprostenol, treprostinil, and iloprost [4, 5]. 
Inhaled prostacyclin analogues have been used for pulmonary vasodilation for vasoreactivity testing, acute cor pulmonale, post-cardiac surgery patients, and those with ARDS $[6,7]$.

\section{Main text \\ COVID-19 associated acute respiratory distress syndrome}

COVID-19 associated acute respiratory distress syndrome (CARDS) is a severe form of SARS CoV-2 infection and affects about $15-30 \%$ of hospitalized patients. The early hypothesis stated that cytokine storm is related to CARDS development since the elevation of serum IL-6, IL-1 $\beta$, and TNF- $\alpha$ was evident. However, a recent comparison prevailed that COVID-19 serum cytokine levels were significantly lower to sepsis and another cytokine release syndrome. Severe COVID-19 pneumonia case definition overlaps with "classic" ARDS. Yet, CARDS is expected to have unique pathophysiological features to "classic" ARDS, namely endothelial barrier disruption followed by intravascular thrombosis, endothelial dysfunction-related hypoxic pulmonary vasoconstriction loss, and exaggerated blood flow to a collapsed lung. A post-mortem examination on CARDS patients revealed a high thrombus burden in pulmonary capillaries, indicating a thrombotic and microangiopathic vasculopathy, compared to "classic" ARDS $[8,9]$.

Recent multicenter studies demonstrated CARDS had the same lung morphology and respiratory mechanics of "classic" ARDS. Subsequently, CARDS patients with low static respiratory compliance and high D-dimer concentration were associated with a higher mortality rate. It is proposed that widespread pulmonary vascular thrombosis, pulmonary vascular endotheliitis, and elevated D-dimers are unique to COVID-19 patients. This intravascular pathology would increase the dead space and hypoxemia in CARDS patients [2, 10]. Besides, the widespread pulmonary vascular thrombosis could result in pulmonary hypertension $(\mathrm{PH})$ and right ventricular dysfunction (RVD) [11]. Previous meta-analysis demonstrated that PH and RVD are prevalent in COVID-19 patients (19\% and $22 \%$, accordingly) and associated with higher mortality, severity, intensive care unit admission, and mechanical ventilation usage [12].

\section{Mechanism of action prostacyclin analogues in ARDS}

Prostacyclin analogues are the most commonly used regimens for pulmonary artery hypertension. It mimics endogenous prostacyclin $\left(\mathrm{PGI}_{2}\right)$ and binds to a G-protein coupled receptor on vascular smooth muscle and platelets surface. Followingly, cyclic adenosine monophosphate (cAMP) is activated and induces pulmonary artery vasodilatation, vascular smooth muscle relaxation, and inhibits platelet aggregation. It also appears to antiproliferative and cytoprotective properties. Available forms of prostacyclin analogues are oral, inhaled, and intravenous [13].

Prostacyclin analogues potentially treat CARDS for at least four rationales. First, inhaled prostacyclin analogues improve oxygenation, V/Q mismatch, and act as an ARDS therapy alternative [13-15]. Although it has not been linked to better patient outcomes and is not commonly recommended, it can be utilized in severe, lifethreatening hypoxia that is resistant to standard ARDS care, as observed in COVID-19 [13].

Second, it alleviates direct SARS-CoV-2-related coagulopathy by controlling platelet activity. Platelet aggregation is inhibited by prostacyclin at high concentrations. A routine dose of prostacyclin analogue would support platelet adherence to the damaged vascular wall and involve in vascular repair, together with thrombus formation. Prostacyclin therapy counteracts the prothrombotic effect of endothelin and may reduce the in situ thrombosis observed in PAH patients and perhaps in CARDS patients $[13,16]$.

Third, prostacyclin elevated nitric oxide production, leading to more antithrombotic and vasodilatation. As with inhaled nitric oxide, prostacyclin's potent endothelial effects, such as preventing vasoconstriction and platelet aggregation, may significantly affect these CARDS. Inhaled prostacyclin has the added advantage of inhaled nitric oxide because it does not necessitate the use of any specific equipment and can be administered directly through a standard ventilator (close circuit) [13].

Finally, prostacyclin and nitric oxide speculatively have essential anti-inflammatory effects, particularly on monocyte/macrophage function, which may benefit COVID-infected patients [13, 17].

\section{Inhaled versus other routes of administration}

Inhaled and oral prostacyclin analogues offer the benefit of avoiding concerns in parenteral administration, such as pain at the infusion site, line discharge, skin and blood infections, and other unfavorable side effects [18]. However, it remains unclear whether such agents that act on the prostacyclin pathway are equally effective whether administered orally or by inhalation. AbuHalimeh et al. [19] presented two cases in which transition from inhaled treprostinil to either oral treprostinil or selexipag, resulting in worsening clinical condition and hemodynamic profile after, subsequently the hemodynamic and clinical profile improved after switched back to inhalation. These divergent responses may reflect either impaired gastrointestinal absorption with lower systemic levels of the drug and/or a preferential (local) action of the inhaled drug specifically on the pulmonary vasculature $[19,20]$. The parenteral 
Table 1 Evidence of inhaled prostacyclin analogues for CARDS

\begin{tabular}{|c|c|c|c|}
\hline References & Study design (sample size) & Regiment & Outcome \\
\hline Filippini et al. [31] & Case report (1) & lloprost & Improved $\mathrm{SpO}_{2}, \mathrm{PO}_{2} / \mathrm{FiO}_{2}$, and $\mathrm{HRCT}$ findings \\
\hline DeGrado et al. [26] & Retrospective observational (38) & Epoprostenol or nitric oxide & No significant improvement in oxygenation metrics \\
\hline Sonti et al. [27] & Retrospective observational (80) & Epoprostenol & $\begin{array}{l}\text { Fifty percent of patients have a clinically significant } \\
\text { improvement in } \mathrm{PaO} 2 / \mathrm{FiO} 2 \text { after the initiation of } \\
\text { epoprostenol }\end{array}$ \\
\hline Li et al. [28] & Retrospective observational (43) & Epoprostenol (some with PP) & $\begin{array}{l}\text { The combination of inhaled epoprostenol and PP } \\
\text { improved oxygenation compared to epoprostenol or } \\
\text { PP individually }\end{array}$ \\
\hline Franco et al. [29] & Randomized controlled trial (actual 11) & Epoprostenol & $\begin{array}{l}\text { Respiratory and cardiac/circulatory failure, oxygena- } \\
\text { tion, time to extubation, ICU days, and hospital days } \\
\text { (ongoing) }\end{array}$ \\
\hline Kharma et al. [30] & Randomized controlled trial (estimated 40) & Iloprost & $\begin{array}{l}\text { Oxygenation parameters, rates of intubation, ventila- } \\
\text { tion duration, ICU and hospital LOS, rates of proning, } \\
\text { ECMO, and mortality (ongoing) }\end{array}$ \\
\hline
\end{tabular}

CARDS, COVID-19 associated acute respiratory distress syndrome; ECMO, extracorporeal membrane oxygenation; HRCT, high resolution computed tomography; LOS, length of stay; $\mathrm{PO}_{2} / \mathrm{FiO}_{2}$, partial pressure arterial oxygen/fraction of inspired oxygen; $\mathrm{PP}$, prone position; SpO2, oxygen saturation

route of treprostinil administration of (IV, SC) is bioequivalent at a steady-state, while oral treprostinil yields systemic exposure similar to that of parenteral administration with approximately $17 \%$ bioavailability. Inhaled treprostinil yields lower systemic concentrations but with delivered locally to the lungs [21].

In general, the side effects of inhaled prostacyclin are flushing, jaw pain, headaches, nausea, vomiting, diarrhea, and dizziness [4]. In different populations, such as heart failure, $\mathrm{PH}, \mathrm{RVD}$, or refractory hypoxemia after cardiothoracic surgery, inhaled prostacyclin is considered safe $[22,23]$. No side effects were reported in both populations. A recent meta-analysis also stated that no side effects such as bleeding and organ dysfunction were reported in ARDS patients receiving inhaled prostacyclin therapy [15].

Whereas, the potential risks and challenges of inhalation therapy in COVID-19 patients include aerosolization and blockage of bacterial/viral filters used in ventilator circuits, particularly in epoprostenol. Therefore, placement of the filter in the expiratory port of the ventilation circuit during inhalation therapy is necessary to minimize aerosolization into the room. In addition, airborne precautions similar to those for intubation should be taken.

Clinical evidence of inhaled prostacyclin analogue in ARDS Clinical experience with inhaled prostacyclin for patients with ARDS suggests that side effects are rare, although published data are limited. Previous Cochrane review by Afshari et al. [15] stated that nebulized iloprost and epoprostenol reduce $\mathrm{PaO}_{2} / \mathrm{FiO}_{2}$ ratio in patients with ARDS. However, their effect on mortality reduction was unknown. Early studies of inhaled iloprost in patients with ARDS and pulmonary hypertension showed improved oxygenation without adverse effects on pulmonary mechanics or systemic hemodynamics [24]. Inhaled epoprostenol may also improve oxygenation in ARDS patients with hypotension as the most common adverse event based on a study by Dunkley et al. [25]

A meta-analysis evaluated the potential of inhaled prostaglandins (including $\mathrm{PGI}_{2}$ ) in ARDS management. The review includes 25 studies consisted of 10 observational studies, 7 case reports/series, 6 non-randomized trials, and 2 randomized controlled trials. Improvements in $\mathrm{PaO}_{2} / \mathrm{FiO}_{2}$ and $\mathrm{PaO}_{2}$ were observed along with reduced pulmonary artery pressure in inhaled prostaglandins group. The baseline oxygenation and ARDS etiology did not interfere with the result. Despite high heterogeneity and risk of bias due to mixed study designs, this metaanalysis provides evidence to support inhaled prostaglandins as ARDS treatment [14].

\section{Clinical evidence and ongoing trials of inhaled prostacyclin analogues in COVID-19}

Several retrospective studies have demonstrated the potential benefit of prostacyclin analogues use, alone or in combination, with better clinical outcomes in COVID-19. A retrospective single-center study by DeGrado et al. [26] reported that in individuals with refractory hypoxemia due to COVID-19, inhaled epoprostenol and inhaled nitric oxide did not elicit meaningful increases in oxygenation parameters. However, the baseline characteristics were markedly different and early administration of inhalation might be beneficial. Sonti et al. [27] also reported clinically significant improvement in $\mathrm{PaO}_{2} / \mathrm{FiO}_{2}$ after the initiation of 
inhaled epoprostenol in 50\% of mechanically ventilated patients. Combination use of inhaled epoprostenol and prone positioning in COVID-19 patients with mechanical ventilation with refractory hypoxemia showed improved oxygenation compared with each treatment individually [28].

To the best of the author's knowledge, there are currently no published prospective or randomized trials on inhaled prostacyclin analogues in CARDS; however, several $[29,30]$ are currently being prepared or are being carried out. A randomized, double-blind controlled trial comparing the effects of inhaled epoprostenol delivered via a breath-actuated delivery system to placebo on oxygen levels and treatment outcomes in mechanically ventilated COVID-19 patients is currently on phase 2 (VPCOVID [NCT04452669]) [29]. Another inhaled prostacyclin analogue, iloprost, was also under investigation in phase 2 of a single-arm clinical trial investigating the use of inhaled iloprost $20 \mathrm{mcg}$ three times daily for five days in suspected or confirmed patients COVID19 with hypoxemic respiratory failure (ILOCOVID [NCT04445246]) [30]. Evidence regarding the use of inhaled prostacyclin in CARDS is summarized in Table 1.

\section{Conclusions}

Despite the lack of high-quality evidence, the use of inhaled prostacyclin analogues is rational as an adjunctive treatment for COVID. Inhaled prostacyclin may be considered in patients with refractory, life-threatening hypoxia despite standard management. The potential benefits include enhanced perfusion preferentially to well-ventilated lung regions, reducing pulmonary pressures, antithrombotic properties, and a relatively good safety profile.

\section{Abbreviations \\ ARDS: Acute respiratory distress syndrome; cAMP: Cyclic adenosine monophosphate; CARDS: COVID-19 associated acute respiratory distress syndrome; COVID-19: Coronavirus disease 2019; PH: Pulmonary hypertension; RVD: Right ventricular dysfunction.}

\section{Acknowledgements}

Not applicable.

\section{Authors' contributions}

EPBM and $\mathrm{KL}$ conceived the idea, designed and drafted the work, revising critically for important intellectual content. All authors revised and approved the version to be published.

\section{Funding}

The authors received no financial support for the research, authorship, and/or publication of this article.

\section{Availability of data and materials}

Not applicable.

\section{Declarations}

Ethics approval and consent to participate

Not applicable.

\section{Consent for publication}

Not applicable.

\section{Competing interests}

The authors declare that they have no competing interests.

\section{Author details}

${ }^{1}$ Department of Cardiology and Vascular Medicine, Faculty of Medicine, Universitas Airlangga - Dr. Soetomo General Hospital, Jl. Mayjen Prof. Dr. Moestopo No.6-8, Surabaya 60286, Indonesia. ${ }^{2}$ Faculty of Medicine, Universitas Airlangga, J. Mayjen Prof. Dr. Moestopo No.6-8, Surabaya 60286, Indonesia.

Received: 20 July 2021 Accepted: 6 September 2021

Published online: 16 September 2021

\section{References}

1. Wu R, Wang L, Kuo HCD, Shannar A, Peter R, Chou PJ et al (2020) An update on current therapeutic drugs treating COVID-19. Curr Pharmacol Rep 6:56-70. https://doi.org/10.1007/s40495-020-00216-7

2. Van Haren FMP, Page C, Laffey JG, Artigas A, Camprubi-Rimblas M, Nunes Q et al (2020) Nebulised heparin as a treatment for COVID-19: scientific rationale and a call for randomised evidence. Crit Care 24:1-11. https:// doi.org/10.1186/s13054-020-03148-2

3. Hasan SS, Capstick T, Ahmed R, Kow CS, Mazhar F, Merchant HA et al (2020) Mortality in COVID-19 patients with acute respiratory distress syndrome and corticosteroids use: a systematic review and meta-analysis. Expert Rev Respir Med 14:1149-1163. https://doi.org/10.1080/17476348. 2020.1804365

4. Searcy RJ, Morales JR, Ferreira JA, Johnson DW (2015) The role of inhaled prostacyclin in treating acute respiratory distress syndrome. Ther Adv Respir Dis 9:302-312. https://doi.org/10.1177/1753465815599345

5. Bethesda (2012) Prostacyclin analogs. National Institute of Diabetes and Digestive and Kidney Diseases

6. Alhazzani W, Møller MH, Arabi YM, Loeb M, Gong MN, Fan E et al (2020) Surviving sepsis campaign: guidelines on the management of critically ill adults with coronavirus disease 2019 (COVID-19). Intensive Care Med 46:854-887. https://doi.org/10.1007/s00134-020-06022-5

7. Konstam MA, Kiernan MS, Bernstein D, Bozkurt B, Jacob M, Kapur NK et al (2018) Evaluation and management of right-sided heart failure: a scientific statement from the American Heart Association. Circulation 137:e578-622. https://doi.org/10.1161/CIR.0000000000000560

8. Attaway AH, Scheraga RG, Bhimraj A, Biehl M, Hatipoğ LU (2021) Severe covid-19 pneumonia: pathogenesis and clinical management. BMJ. https://doi.org/10.1136/bmj.n436

9. Wu C, Chen X, Cai Y, Xia J, Zhou X, Xu S et al (2020) Risk factors associated with acute respiratory distress syndrome and death in patients with coronavirus disease 2019 pneumonia in Wuhan, China. JAMA Intern Med 180:934-943. https://doi.org/10.1001/jamainternmed.2020.0994

10. Grasselli G, Tonetti T, Protti A, Langer T, Girardis M, Bellani G et al (2020) Pathophysiology of COVID-19-associated acute respiratory distress syndrome: a multicentre prospective observational study. Lancet Respir Med 8:1201-1208. https://doi.org/10.1016/S2213-2600(20)30370-2

11. Park JF, Banerjee S, Umar S (2020) In the eye of the storm: the right ventricle in COVID-19. Pulm Circ. https://doi.org/10.1177/2045894020936660

12. Oktaviono YH, Mulia EPB, Luke K, Nugraha D, Maghfirah I, Subagjo A (2021) Right ventricular dysfunction and pulmonary hypertension in COVID-19: a meta-analysis of prevalence and its association with clinical outcome. Arch Med Sci. https://doi.org/10.5114/aoms/136342

13. Franco V, Bradley EA, Badagliacca R, Sabanayagam A, Rajpal S, Lastinger LT et al (2020) Pulmonary vasodilators: beyond the bounds of pulmonary arterial hypertension therapy in COVID-19. Pulm Circ 10:2045894020970369. https://doi.org/10.1177/2045894020970369 
14. Fuller BM, Mohr NM, Skrupky L, Fowler S, Kollef MH, Carpenter CR (2015) The use of inhaled prostaglandins in patients with ARDS: a systematic review and meta-analysis. Chest 147:1510-1522. https://doi.org/10.1378/ chest.14-3161

15. Afshari A, Bastholm Bille A, Allingstrup M (2017) Aerosolized prostacyclins for acute respiratory distress syndrome (ARDS). Cochrane Database Syst Rev. https://doi.org/10.1002/14651858.CD007733.pub3

16. Sakamaki F, Kyotani S, Nagaya N, Sato N, Oya H, Satoh T et al (2000) Increased plasma P-selectin and decreased thrombomodulin in pulmonary arterial hypertension were improved by continuous prostacyclin therapy. Circulation 102:2720-2725. https://doi.org/10.1161/01.CIR.102. 22.2720

17. Schroder K, Hertzog PJ, Ravasi T, Hume DA (2004) Interferon- $\gamma$ : an overview of signals, mechanisms and functions. J Leukoc Biol 75:163-189. https://doi.org/10.1189/jlb.0603252

18. McLaughlin VV, Benza RL, Rubin L, Channick RN, Voswinckel R, Tapson VF et al (2010) Addition of inhaled treprostinil to oral therapy for pulmonary arterial hypertension: a randomized controlled clinical trial. J Am Coll Cardiol 55:1915-1922. https://doi.org/10.1016/j.jacc.2010.01.027

19. AbuHalimeh BJ, Parambil JG, Tonelli AR (2017) Different efficacy of inhaled and oral medications in pulmonary hypertension. Hear Lung J Acute Crit Care 46:334-337. https://doi.org/10.1016/j.hrtlng.2017.04.010

20. Mitchell JA, Ahmetaj-Shala B, Kirkby NS, Wright WR, Mackenzie LS, Reed DM et al (2014) Role of prostacyclin in pulmonary hypertension. Glob Cardiol Sci Pract 2014:53. https://doi.org/10.5339/gcsp.2014.53

21. Kumar P, Thudium E, Laliberte K, Zaccardelli D, Nelsen A (2016) A comprehensive review of treprostinil pharmacokinetics via four routes of administration. Clin Pharmacokinet 55:1495-1505. https://doi.org/10. 1007/s40262-016-0409-0

22. Huang CY, Lee JK, Chen ZW, Cheng JF, Chen SY, Lin LY et al (2020) Inhaled prostacyclin on exercise echocardiographic cardiac function in preserved ejection fraction heart failure. Med Sci Sports Exerc 52:269-277. https:// doi.org/10.1249/MSS.0000000000002145

23. De Wet CJ, Affleck DG, Jacobsohn E, Avidan MS, Tymkew H, Hill LL et al (2004) Inhaled prostacyclin is safe, effective, and affordable in patients with pulmonary hypertension, right heart dysfunction, and refractory hypoxemia after cardiothoracic surgery. J Thorac Cardiovasc Surg 127:1058-1067. https://doi.org/10.1016/j.jtcvs.2003.11.035

24. Sawheny E, Ellis AL, Kinasewitz GT (2013) Iloprost improves gas exchange in patients with pulmonary hypertension and ARDS. Chest 144:55-62. https://doi.org/10.1378/chest.12-2296

25. Dunkley KA, Louzon PR, Lee J, Vu S (2013) Efficacy, safety, and medication errors associated with the use of inhaled epoprostenol for adults with acute respiratory distress syndrome: a pilot study. Ann Pharmacother 47:790-796. https://doi.org/10.1345/aph.1R540

26. DeGrado JR, Szumita PM, Schuler BR, Dube KM, Lenox J, Kim EY et al (2020) Evaluation of the efficacy and safety of inhaled epoprostenol and inhaled nitric oxide for refractory hypoxemia in patients with coronavirus disease 2019. Crit Care Explor 2:e0259. https://doi.org/10.1097/cce.00000 00000000259

27. Sonti R, Pike CW, Cobb N (2021) Responsiveness of inhaled epoprostenol in respiratory failure due to COVID-19. J Intensive Care Med 36:327-333. https://doi.org/10.1177/0885066620976525

28. Li J, Fink JB, Augustynovich AE, Mirza S, Kallet RH, Dhand R (2020) Effects of inhaled epoprostenol and prone positioning in intubated coronavirus disease 2019 patients with refractory hypoxemia. Crit Care Explor 2:e0307. https://doi.org/10.1097/cce.0000000000000307

29. Franco V (2020) Venta prost in subjects with COVID-19 requiring mechanical ventilation. ClinicalTrialsGov

30. Kharma N (2020) Inhaled iloprost for suspected COVID-19 respiratory failure. ClinicalTrialsGov

31. Filippini A, Bnà C, Bellosta R, Bazzani R, Luzzani L, Pegorer MA et al (2021) COVID-19 acute respiratory distress syndrome: can iloprost have a role for the treatment? Respir Med Case Rep. https://doi.org/10.1016/j.rmcr.2021. 101358

\section{Publisher's Note}

Springer Nature remains neutral with regard to jurisdictional claims in published maps and institutional affiliations.

\section{Submit your manuscript to a SpringerOpen ${ }^{\odot}$ journal and benefit from:}

- Convenient online submission

- Rigorous peer review

- Open access: articles freely available online

- High visibility within the field

- Retaining the copyright to your article

Submit your next manuscript at $\boldsymbol{\Delta}$ springeropen.com 